\title{
Esporte olímpico e paraolímpico: coincidências, divergências e especificidades numa perspectiva contemporânea
}

CDD. 20.ed. 796.05

796.48
Renato Francisco Rodrigues MARQUES ${ }^{* / * * * * * * * * * *}$

Edison DUARTE*

Gustavo Luis GUTIERREZ*

José Júlio Gavião de ALMEIDA*

Tatiane Jacusiel MIRANDA*

\section{Resumo}

Este texto apresenta uma análise do esporte adaptado, tendo como objeto principal os Jogos Paraolímpicos, evento realizado de forma associada com os Jogos Olímpicos. Procura apontar similaridades e diferenças entre os dois eventos, considerando-os como formas de expressão do esporte contemporâneo, destacando características como a organização, relação com o mercado de consumo e formas de divulgação. As principais diferenças descritas se referem à gênese dos dois objetos, além da maior vocação do esporte olímpico para a inserção mercadológica. Quanto às similaridades, destaca-se a presença em ambos das caracteristicas do esporte moderno gerado no século XIX, além das estruturas organizacionais conceitualmente similares. Podem-se apontar ainda alguns pontos específicos do esporte adaptado, como modalidades próprias, a exemplo do "Goalball".

Unitermos: Sociologia do esporte; Esporte adaptado; Olimpiadas; Paraolimpíadas.

\section{Introdução}

Estudar esporte na cultura atual significa tentar compreender o seu papel, suas formas de manifestação e os valores que transmite para a sociedade. Nessa questão insere-se, entre outros objetos, os esportes adaptados, representados, num âmbito mundial, inclusive pelo esporte paraolímpico.

A sociologia se ocupa do esporte desde o século XIX, procurando avançar na reflexão sobre aspectos como sua origem, importância e as relaçôes culturais, de poder e religiosas que o permeiam. Nesta relação, a área da sociologia tanto fornece subsídios para a sociologia do esporte, quanto recebe contribuiçōes dela para suas diversas disciplinas temáticas (PILZ, 1999).

As transformaçōes sociais do fenômeno esportivo e os impactos ou influências dele sobre os hábitos dos indivíduos que tomam contato com esse universo, ou seja, as inter-relações entre a manifestação do fato esportivo e a sociedade constituem o objeto da área de conhecimento. Nesse processo, é importante considerar que, enquanto objeto de estudo, o esporte tem sua evolução, valores e conquistas atrelados à sociedade em que se insere, ou seja, é uma prática que deve ser contextualizada no tempo e no espaço da sua socialização. $\mathrm{O}$ objetivo deste trabalho, portanto, é investigar a partir de um referencial teórico ligado às Ciências Humanas, mais precisamente à Sociologia do Esporte, as relações estruturais, históricas e comerciais entre o esporte olímpico e o esporte paraolímpico, na sociedade contemporânea.

O texto apresenta, num primeiro momento, e sob uma perspectiva sócio-histórica, categorias e princípios da gênese do esporte moderno e a sua transformação em esporte contemporâneo. Num segundo momento, caracteriza o esporte paraolímpico como um objeto que herda características do esporte olímpico, principalmente da sua manifestação moderna, e que se configura como um fenômeno em processo de expansão. Numa terceira etapa, busca estabelecer formas de relação entre os objetos para ilustrar as etapas de desenvolvimento durante a história do esporte olímpico e paraolímpico, e apontar especificidades de cada um deles.
*Faculdade de Educação Física, Universidade Estadual de Campinas.

**Fundação Municipal de Ensino Superior de Bragança Paulista.

***Faculdade de Jaguariúna.

**** Centro Universitário Amparense. 
Parte-se da definição de esporte como um fenômeno sócio-cultural que engloba diversas práticas humanas, norteadas por regras de ação próprias e institucionalizadas, direcionadas para um aspecto competitivo, seja ele caracterizado pela oposiçāo entre sujeitos ou pela comparação entre realizaçôes do próprio indivíduo,

\section{O esporte olímpico}

\section{A gênese do esporte moderno e a origem do olimpismo}

O esporte teve sua gênese na Inglaterra do século XVIII, por se tratar de um país em processo de pacificação e racionalização de suas práticas, como ocorreu também no lazer, implicando na institucionalização dos jogos populares e práticas corporais (Elias \& DunNNING, 1992).

Alguns autores (DunNing \& CURRY, 2006; EliAs \& DunNing, 1992) descrevem como características geradoras do esporte moderno, o declínio da propensão das pessoas em obter prazer por meio da participação direta ou indireta em atos de violência física, e a preferência pela existência prévia de um grau mínimo de cooperação não violenta entre os participantes.

O primeiro movimento significativo no sentido de modernização dos jogos populares ocorreu no século XIX, nas escolas públicas inglesas, simbolizando a gênese do esporte moderno. Essas instituições se caracterizavam por grande disciplina interna, abusos físicos dos mais velhos sobre os mais novos e autonomia dos alunos nas suas práticas de tempo livre (Rubio, 2002). Nesse contexto, os jogos, que antes eram transmitidos de forma oral, de geração por geração, passaram a sujeitar-se a restrições impostas por regras escritas, muitas delas relacionadas à exclusão ou controle da violência, tornando os jogos mais "civilizados" (DunNing, 1992).

As escolas públicas eram frequentadas por alunos de classes sociais privilegiadas e tinham a função principal de transmitir valores morais ligados à coragem, tolerância ao sofrimento, altruísmo, competitividade, respeito a normas, virilidade, entre outros, pois formavam os homens que iriam atuar na indústria, comércio e administração do império (RUBIO, 2002). Os jogos eram uma estratégia utilizada com esse fim, além de promover a disciplina entre os alunos, visto que atraía a atenção e interesse dos jovens.

Os jogos populares passaram, então, por um processo de racionalização dentro das escolas, de que se manifestam através da atividade corporal. Essas práticas podem ou não se expressar através de confrontos diretos entre sujeitos, mas sempre expressam o desejo de realização do ser humano, que encarna a necessidade, entre outras, de emocionar-se, superarse, jogar, brincar e comunicar-se (MARQUES, 2007).

modo a terem suas regras escritas e orientadas de acordo com as normas de cada uma dessas instituiçôes. Cada unidade escolar, ou cada região, possuía formas de normatização próprias, havendo a criação de inúmeros jogos, e diversas formas de praticar um mesmo jogo (WADDINGTON, 2006).

Com o sentido de modernização da sociedade inglesa, melhoria dos meios de transporte e consequente maior intercâmbio cultural entre as regiōes, o esporte passou por um de seus importantes estágios de transformação, no qual rumou para uma uniformização das regras através do surgimento de órgãos reguladores, visto que a heterogeneidade de normatizaçôes impossibilitava encontros para jogos entre instituiçôes de locais diferentes. Essa transformação estabeleceu um dos aspectos que vêm a diferenciar o esporte de manifestaçôes culturais anteriores à sua gênese: a racionalização e universalização de suas normas.

Esse processo se deu de acordo com os seguintes passos, a exemplo do "Football" e do "Rugby" (DunNing \& CurRY, 2006): escrita das regras; demarcação do tamanho e forma das áreas de jogo; imposição de limitações à duração dos jogos; redução do número de jogadores; igualdade do número de jogadores entre as equipes; regulamentos estritos com relação ao uso da força física. GUTTMANN (1978, p.16) aponta algumas categorias, construídas historicamente, que definem o esporte moderno: secularidade (rompimento com o sagrado, espiritual); igualdade de chances na disputa; especialização dos papéis; racionalização das práticas e processos; burocracia; quantificação; recordes.

Devido à seriedade crescente do fenômeno, derivada da representatividade e dos resultados das competições entre as equipes, o esporte amador começou a dividir espaço com o profissional, o qual exigia melhor performance, e consequente maior dedicação dos atletas. O processo de profissionalização ajudou o esporte a tornar-se popular, pois produziu uma massificação de suas práticas e significados. $\mathrm{O}$ amadorismo restringia os grupos às reuniōes de 
sujeitos homogêneos socialmente, devido ao significado atribuído a essa prática perante o complexo social (MARCHI JUNIOR, 2002).

Nesse momento do processo, deu-se início ao embate entre a ideologia amadora (aristocrática, com objetivo de "elitizar" a prática e fazê-la um instrumento de diferenciação social) e profissional (burguesa, com o objetivo de produzir capital com o esporte, através de sua divulgação). É devido à busca da afirmação da supremacia social aristocrática que os Jogos Olímpicos, elaborados por um barão (Coubertin) no final do século XIX, têm princípios amadores. Seus ideais valorizavam a cultura da nobreza, num período em que a burguesia era culturalmente hegemônica e as classes populares também ganhavam certo espaço, em detrimento da aristocracia (PRONI, 1998).

Surge, nesse período, o Olimpismo, que procurou justificar e nortear a criação dos Jogos Olímpicos modernos como um fenômeno internacional que transmitia valores da nobreza. O Olimpismo se caracteriza como uma filosofia, exaltando as qualidades do corpo, espírito e mente através do esporte, associado com valores educacionais de bom exemplo e respeito aos princípios éticos universais (COMITÊ Olímpico Internacional, 2007). Seu objetivo é colocar o esporte a serviço do desenvolvimento harmonioso do Homem, promovendo uma sociedade de paz e preservação dos direitos e dignidade humana. Todas as formas de discriminação, sejam ligadas a origem, raça, religião ou política, são incompatíveis com os princípios olímpicos (СомITÊ Olímpico InTERNACIONAL, 2007).

\section{Atransiçãoparao esportecontemporâneo e suas formas de manifestação: a consequente transformação dos jogos olímpicos}

O esporte sofreu e sofre transformações constantes em sua história, de acordo com mudanças no meio social, o que colabora para formar o fenômeno que se apresenta na sociedade contemporânea. Considerando seus mais de dois séculos de vida, podem-se observar mudanças em sua conformação, derivadas de transformaçôes no universo social que o cerca, numa comparação entre o fenômeno de hoje e o gerado no século XIX na Inglaterra (MARQUES, 2007).

As transformaçōes sofridas pelo esporte moderno, no sentido de conformação do fenômeno contemporâneo, foram graduais, tanto através de mudanças de paradigmas, que seguem tendências mais amplas presentes na sociedade, quanto por marcos históricos. Tais processos começaram a ocorrer, de forma mais significativa, após a $2^{\mathrm{a}}$. Guerra Mundial, quando o uso político, a popularização, mundialização e espetacularização do fenômeno tomaram maiores proporçôes, com seu ápice no final da Guerra Fria.

No início do século XX o esporte sofreu uma mudança qualitativa em sua estruturação e divulgação, em razão de dois movimentos básicos: Transformação das estruturas sociais e econômicas, principalmente após a $2^{\text {a. }}$ Guerra Mundial; Progressiva mercantilização da cultura (PRONI, 1998).

Essa transformação não se deu como uma ruptura pontual que leva ao surgimento de um fenômeno totalmente novo, ao contrário do que ocorreu no século XVIII. A modificação resultou de adaptações do fenômeno moderno a novas configurações sociais, gerando um objeto diferente. O esporte contemporâneo se faz herdeiro do esporte moderno quanto à sua identidade como campo social (campo esportivo), porém, original quanto às suas formas de manifestação e a seus símbolos, signos e objetivos. Nesse período de transição, o esporte tomou importância política, devida sua capacidade de comparações de performances e de enfrentamento entre nações (MARQUeS, 2007).

No período entre as duas grandes guerras mundiais nota-se a valorização do uso político do esporte em âmbitos nacional e internacional, quando os governos passam a explorar melhor a capacidade que o fenômeno esportivo tem de atrair o interesse das populaçóes, e se apresentar como uma possibilidade de comparação direta de performances numa única linguagem, pautada em normas universais. Como exemplo disso tem-se a organização das Olimpíadas de Berlin, em 1936. No caso, notava-se a destacada intenção do estado nazista em demonstrar a superioridade da raça ariana. Até esse período, quando o esporte começa a tomar proporçôes de espetáculo (nesse caso voltado à política), os Jogos Olímpicos não faziam muito sucesso. Isto muda com o incremento de seu uso político pelos governos, e consequente aumento da divulgação (TuBino, 1997).

Após a 2a. Guerra Mundial, com a separação das grandes potências mundiais em dois blocos econômicos, o esporte passou a ser uma forma de manifestar superioridade frente a outros povos e ferramenta política para os Estados. O aumento de investimentos no alto rendimento, e a representatividade exercida por atletas em encontros internacionais, ajudam na sua expansão. Com a entrada da União Soviética nos Jogos Olímpicos de 1952, 
em Helsinke, Finlândia, e com o financiamento das modalidades olímpicas por parte dos Estados Unidos, o investimento dos estados no esporte aumentou de forma substancial (TuBINO, 1992). Ocorre nesse período o fortalecimento da perspectiva espetacular do esporte, já que a eficiência do seu uso político dependia de sua divulgação, tornando-o uma manifestação cultural importante, que gerasse interesse e que unificasse formas de comunicação a nível global. Isso ampliou seus limites geográficos e culturais, tornando-o mais conhecido e valorizado em todo o planeta. Porém, também abriu a possibilidade de surgirem novas formas de manifestação, devido à sua interface com inúmeras formas de cultura diferentes (MARQUES, 2007).

$\mathrm{O}$ uso ideário-político do esporte teve seu ápice durante o período da Guerra Fria. Posteriormente, com a queda do muro de Berlin, os investimentos mudaram de sentido. Além da finalidade política, inerente à sua capacidade de mobilizar grandes multidóes, o esporte começou a chamar a atenção também pelo seu potencial mercadológico. Isso ocorreu devido ao aumento das proporções de divulgação e influência cultural das competições esportivas, principalmente dos Jogos Olímpicos, que passaram a atrair um enorme público mundial e a representar um valioso mercado em potencial.

Com o fim da Guerra Fria e o fortalecimento da globalização, o esporte, antes pautado principalmente pela disputa político-ideológica, rumou no sentido da disputa mercadológica entre marcas e fornecedores, que aproveitam o grande interesse por este fenômeno e financiam o espetáculo (MARQUES, 2007). Tais transformaçôes afetaram também o esporte olímpico que, de uma perspectiva totalmente amadora, viu-se envolvido no mundo da profissionalização e consumo de suas práticas e símbolos.

É nesse aspecto que mora a principal transformação do esporte moderno em contemporâneo, a mercantilização da prática. Embora no fenômeno moderno já fosse possível observar manifestações de profissionalismo e investimentos externos, é após a $2^{\text {a. }}$ Guerra Mundial que esse movimento se intensifica e toma proporçôes de produto a ser consumido em diversos campos da sociedade (MARQUES, 2007).

Outra característica importante do esporte contemporâneo é a institucionalização de sentidos diferentes da prática esportiva, que transcendem a hegemonia do alto rendimento. Isso se apresenta como práticas alternativas e formas específicas de aproximação dos sujeitos ao universo esportivo, onde surgem ideias referentes à promoção da saúde, valores educacionais, inclusão social e diversão, entre outras.
Por isso, nota-se interesse sobre as diferentes faces do esporte contemporâneo tanto por órgãos de mercado (pela aproximação e familiarização desse fenômeno ao grande público por meio de práticas variadas), quanto das políticas públicas (MARQUES, 2007).

O crescimento da divulgação e o aumento do alcance das práticas esportivas e os produtos a ela vinculados (ídolos, materiais esportivos, transmissôes televisivas, entre outros) fazem com que o esporte seja interpretado e transformado de acordo com os sujeitos que o incorporam em suas vidas. Isso gera um caráter heterogêneo próprio do fenômeno contemporâneo e não observável no esporte moderno (MARQUes, 2007).

Nesse processo, o esporte contemporâneo se caracteriza como um fenômeno ligado ao mercado, no qual suas práticas, voltadas ao lazer, à educação formal e ao alto rendimento, acabam ou se associando com giro de capital, ou sofrendo influência cultural de um modelo hegemônico. Nesse universo, os meios de comunicação exercem um papel de destaque, o de divulgar e expandir os conceitos, costumes, símbolos, valores e produtos do esporte. A mercantilização do esporte contemporâneo se apresenta sob diversos aspectos, como comércio de possibilidades de prática de lazer, mercado de artigos esportivos ou associados a este fenômeno, meios de informação, ou através do esporte-espetáculo, sendo esta última a forma de expressão que exerce mais influência sobre esse processo, difundindo uma cultura esportiva de consumo.

Quanto às inúmeras formas de manifestação do fenômeno contemporâneo, é possível afirmar que o esporte apresenta traços diferentes de acordo com o ambiente em que se insere (STIGGer, 2005). Cada sujeito se apropria das regras e normas do esporte de acordo com sua perspectiva e transforma a prática a partir desse mesmo modelo. Esse processo denomina-se efeito de apropriação, no qual o sujeito se apodera da prática, moldando-a de acordo com seus interesses e história pessoal (Bourdieu, 1990). Por isso, é possível afirmar que para compreender as diversas manifestações esportivas é preciso considerar o seu significado para os participantes (STIGGER, 2005).

Nesse sentido, MARQUES (2007) propóe o Modelo de concepção das formas de manifestação do esporte, que procura compreender as diversas formas de manifestação do fenômeno contemporâneo, com a intenção de oferecer subsídios para melhor direcionamento de suas práticas às necessidades $\mathrm{e}$ expectativas dos sujeitos que com ele se relacionam. Considera-se, neste modelo, que toda forma de manifestação do esporte contemporâneo se 
configura na relação entre três esferas: ambiente da prática, modalidade da prática, sentido da prática.

$\mathrm{O}$ ambiente da prática engloba a esfera social em que se realiza a prática esportiva. Diz respeito aos meios profissional (alto rendimento), não-profissional (lazer) e escolar. É o campo de realizações nos quais as modalidades esportivas se concretizam, pautadas em sentidos que a contextualizam e lhe dão significado.

A modalidade da prática diz respeito às diversas modalidades esportivas que se caracterizam por regras, normas de ação e formas de disputa próprias, e compõem universos diferentes. São autônomas quanto às suas determinações legais e, em alguns casos, à sua história. Muitas delas têm entidades reguladoras próprias (federações, associações, confederações, ligas, entre outras) que normatizam e regulam a prática. São exemplos de modalidades esportivas o futebol, o boxe, a natação, o "badminton", entre outras.

O sentido da prática diz respeito às razões e os valores transmitidos por ela. $\mathrm{O}$ sentido deriva das condiçôes sociais, culturais e históricas dos indivíduos envolvidos, que exercerão influência sobre a concepção da atividade, e lhe dão significado. Podem ser compreendidos como Esporte oficial ou Esporte re-significado (MARQUES, 2007).

O esporte oficial, pautado na formalidade e regras determinadas por órgãos reguladores, por ser um modelo hegemônico e formalizado, pode ser observado nos três ambientes. $\mathrm{O}$ esporte re-significado, por sua vez, é próprio do ambiente escolar e de lazer, já que se trata, como o próprio nome aponta, de uma re-significação da prática hegemônica (MARQuES, Gutierrez \& AlmeidA, 2008).

\section{O esporte paraolímpico}

\section{Conceito e história}

A sociedade contemporânea se depara com o fenômeno esportivo como um objeto heterogêneo muito presente em seu cotidiano. Suas varias formas de manifestação representam diversas expressões e interpretaçóes culturais, que se adaptam de acordo com as necessidades, expectativas, objetivos e limitações dos sujeitos envolvidos com suas práticas (Marques, Gutierrez \& Almeida, 2006). Uma forma, que cresce em importância a cada dia, objetiva a inserção de pessoas com deficiência no mundo esportivo, a partir da adaptação das práticas. $\mathrm{O}$ princípio da inclusão consiste na incorporação
A comparação entre duas formas de manifestação do esporte serve de exemplo da utilização do modelo. Por um lado, um campeonato profissional de basquetebol tem um sentido (oficial), deriva de uma modalidade específica do esporte (basquetebol) e se apresenta num ambiente (alto rendimento). Por outro, um grupo de idosos que se reúne para jogar voleibol (modalidade), visando diversão e a possibilidade de praticar atividade física (sentido: re-significado), com equipes que se revezam e regras adaptadas às suas necessidades, intenções e limitaçôes (esporte de lazer) também pratica esporte, sob outra forma de manifestação. Ambos os grupos estão envolvidos com a prática esportiva, porém sob aspectos diferentes e expostos a situaçôes e valores distintos.

É nesse campo social que se instalam os atuais Jogos Olímpicos. Assim como o fenômeno esportivo moderno, este evento sofreu transformaçóes estruturais e influências da sociedade contemporânea, principalmente a partir da década de 90, com destaque às mudanças em sua administração, organização e objetivos. Visto como exemplo, a participação liberada para atletas profissionais de basquetebol desde os Jogos Olímpicos de 1992 em Barcelona, Espanha (LANCELOTTI, 1996).

Por essa razão, pode-se afirmar que os Jogos Olímpicos não são mais os mesmos da época de sua criação, em 1896. Este evento, embora ainda busque transmitir valores morais ligados ao olimpismo, incorpora as transformações sociais do fenômeno esportivo e também se pauta na sua própria comercialização, além de se apoiar no ambiente de alto rendimento e sentido oficial das práticas.

de corpos que se encontram fora dos padrões de normalidade (física, fisiológica, comportamental, social) estipulados por determinado grupo social, e que necessitam de superação e compreensão daqueles inseridos nos padrões de normalidade para serem aceitos. O movimento de inclusão é uma forma elaborada que procura, através de ações articuladas, adaptar a pessoa com deficiência à sociedade e viceversa (DUARTE\& SANTOS, 2003).

Logo, essa adaptação, que pode ser definida como a capacidade da pessoa estar apta a atender às demandas exigidas pela vida através de um processo constante, faz-se em dupla via, visto que não existe para a pessoa com deficiência uma adaptação unilateral. Ela tem 
que ocorrer da pessoa com deficiência para com o seu meio e desse ambiente para com o sujeito (DUARTE \& Santos, 2003). Nesse sentido, os processos de adaptação das práticas e atividades, na sociedade contemporânea, visam facilitar a vida de pessoas com deficiência. Por um lado, favorecem sua inclusão social através de meios apropriados, por outro, possibilitam seu crescimento pessoal através da oferta de desafios e necessidade de superação.

O esporte adaptado é um exemplo desse processo. Esse termo parece mais adequado do que "esporte para pessoas com deficiência", pois abrange um leque maior de possibilidades. Pode ser definido como o fenômeno esportivo modificado ou criado para suprir as necessidades dos envolvidos (PACIOREK, 2004), ou diretamente vinculados às pessoas com deficiência (WInNICK, 2004). Pode ser praticado em ambientes integrados, em que as pessoas com deficiência interagem com não-deficientes, ou em ambientes especiais, nos quais a participação é reservada a tais indivíduos (WINNICK, 2004).

Essa vertente do esporte se apresenta na sociedade contemporânea em diversos ambientes e sob diferentes formas, porém existe um movimento que se destaca: o esporte paraolímpico, principal meio de divulgação do esporte adaptado, que tem nos Jogos Parolímpicos seu principal evento em nível mundial.

A palavra "paraolímpico" deriva da preposição grega "para", que signfica "ao lado, paralelo" e da palavra "olímpico", numa referência à ocorrência paralela entre os Jogos Olímpicos e Paraolímpicos desde 1960. A palavra "paraolímpico" era originalmente uma combinação de paraplégico e olímpico, entretanto, com a inclusão de outros grupos de pessoas com deficiência, e a união das associações ao movimento olímpico, ela tomou outra conotação (SEnAtore, 2006).

Existem registros de aparições do esporte adaptado datados de 1871, na School of Deaf, de Ohio, Estados Unidos, que foi a primeira escola para surdos a oferecer beisebol (WINNICK, 2004). As primeiras notícias da existência de clubes esportivos para pessoas surdas datam de 1888 , em Berlim, Alemanha. Porém, somente em 1924 é que foram realizados, em Paris, França, os primeiros "Jogos do Silêncio", com a participação de 145 atletas de nove países europeus. Essa foi a primeira competição internacional para pessoas com deficiência (SENATORE, 2006; WINNICK, 2004).

Quanto aos Jogos Paraolímpicos, a versão dos Jogos Olímpicos para o esporte adaptado, surge a partir do final da $2^{\text {a. }}$ Guerra Mundial. Um espólio perceptível desse marco histórico, principalmente nos países europeus envolvidos no grande conflito, foi o considerável número de combatentes que sofreram lesões na coluna vertebral, ficando paraplégicos ou tetraplégicos. Esta situação influenciou Ludwig Guttmann, neurocirurgião alemão, a iniciar um trabalho de reabilitação médica e social de veteranos de guerra por meio de praticas esportivas, no Centro Nacional de Lesionados Medulares de Stoke Mandeville, Inglaterra, fundado em 1944 pelo próprio cirurgião (COMITÊ ORGANIZADOR DOS Jogos Parapanamericanos, 2007).

O sucesso do trabalho motivou o Doutor Guttmann a organizar a primeira competição para atletas em cadeiras de rodas em 29 de julho de 1948 - exatamente na mesma data de abertura dos Jogos Olímpicos de Londres, a "Stoke Mandeville Games" (SENATORE, 2006). A primeira competição se deu com 16 atletas paraplégicos (14 homens e duas mulheres), na disputa de arco e flecha (LANDRY, 1995).

Em 1952, ex-soldados holandeses se uniram para participar dos Jogos de Stoke Mandeville, e juntamante com os ingleses, fundaram a ISMGF - International Stoke Mandeville Games Federation - Federação Internacional dos Jogos de Stoke Mandeville, dando início ao movimento esportivo internacional que viria a ser base para a criação do que hoje é conhecido como esporte paraolímpico (SENATORE, 2006).

Em 1960, o comitê organizador dos jogos de Stoke Mandeville realizou as competiçóes em Roma, Itália, logo após os Jogos Olímpicos, utilizando os mesmos espaços esportivos e o mesmo formato das Olimpíadas. Quatrocentos atletas de 23 países participaram dos primeiros Jogos Paraolímpcos. Esses jogos ocorriam de quatro em quatro anos, e eram exclusivos para atletas com lesão medular até 1976, quando nos jogos de Toronto, Canadá, houve a inclusão dos atletas cegos e amputados, e a partir de 1980, em Arnhem, na Holanda, a inclusão dos paralisados cerebrais. Além disso, em 1976, em Ornskoldsvik, na Suécia, foram realizados os primeiros Jogos Paraolímpicos de inverno, sendo que este ocorreu no mesmo ano dos jogos de verão até 1992, quando o ciclo foi ajustado em 1994 (Senatore, 2006).

Os Jogos Paraolímpicos sempre foram realizados no mesmo ano dos Jogos Olímpicos, porém nem sempre nos mesmos locais, em períodos próximos (logo em seguida) e utilizando as mesmas instalações. Isto só vai ocorrer de forma definitiva a partir de 1988, em Seul, Coréia do Sul. Em Atenas, Grécia, 
em 2004, celebrou-se a XII Paraolimpíada de verão, com participação de 3.806 atletas de 136 países (Comitê Paraolímpico Internacional, 2008). Dessa forma, os Jogos Paraolímpicos, que começaram como um evento com fortes implicações sociais e fins terapêuticos, tornaram-se o evento esportivo mais importante para as pessoas com deficiência em âmbito mundial.

\section{Classificação médica, funcional e órgãos reguladores}

O esporte paraolímpico tem como protagonista o atleta com deficiência. Tradicionalmente, os competidores pertencem a seis diferentes grupos no Movimento Paraolímpico (Comitê Organizador dos Jogos Parapanamericanos, 2007):

- Atleta com paralisia cerebral;

- Atleta com lesão medular / poliomelite;

- Atleta com amputação;

- Atleta com deficiência visual;

- Atleta com deficiência intelectual;

- "Les autres" (inclui todos os atletas com alguma deficiência de mobilidade não incluída nos grupos acima).

As diferentes formas de deficiência colocam, para os organizadores dos Jogos, o problema de encontrar um sistema que garanta o princípio de igualdade de condições na disputa, levando resultados justos no final das competiçóes. A solução encontrada foi agrupar os competidores em categorias de acordo com o comprometimento apresentado. Surgem então os sistemas de classificação, que têm por objetivo garantir a legitimidade das competições e seus resultados, além de ajudar na prevenção de lesões (PACiOReK, 2004). Os atletas competem dentro de suas categorias, definidas de forma específica por modalidade.

Existem dois tipos de sistemas de classificação, o médico (que verifica o nível mínimo de deficiência e não leva em conta a capacidade funcional do atleta) e o funcional (que identifica como o atleta executa as habilidades específicas da modalidade). Tais instrumentos combinam informações médicas com dados sobre desempenho, a fim de avaliar habilidades específicas da modalidade esportiva que são necessárias. Esse sistema de classificação pode ser usado em competiçóes que envolvam uma ou mais deficiências (PACIOREK, 2004).

Os sistemas de classificação são constantemente reavaliados e questionados na tentativa de promover sempre o sentido de igualdade e justiça nas disputas. Por exemplo, pode-se citar a dificuldade em estabelecer uma escala para deficientes mentais por não haver um sistema fidedigno para tal apontamento. Por essa razão, existe a decisão, por parte do comitê organizador dos Jogos Paraolímpicos, sobre a nãoparticipação desses atletas até as Paraolimpíadas de 2008, pois a partir de 2009, o sistema de classificação, que atualmente é de responsabilidade desse órgão regulador, passará a ser gerenciado pela entidade responsável por cada modalidade esportiva, cabendo a elas definir as normas de participação dos atletas (SEnATORE, 2006).

Esse processo de agrupamento dos participantes em função de sua deficiência gera o surgimento de classes, as quais indicam o grau de comprometimento dos mesmos para participação nas disputas. Atletas com deficiência visual são avaliados por critérios médicos, enquanto que comprometimentos físico-motores, pelo sistema funcional. Quando um atleta tem mais de uma deficiência, deve escolher em qual classe irá competir.

As classes são definidas por modalidades, fazem parte de suas regras específicas e são determinadas por uma variedade de processos que podem incluir avaliação física, técnica, médica e observações dentro e fora das competições (COMITÊ OrGANIZADOR DOS Jogos Parapanamericanos, 2007).

A classe de um atleta é expressa através de um número que não é transferível de uma modalidade esportiva à outra. Caso o atleta queira mudar de modalidade, deverá passar por nova classificação. Geralmente, esse número é precedido pela inicial da modalidade esportiva em inglês. $\mathrm{Na}$ natação, por exemplo, antes dos números tem-se a letra "S", de "swimming". No caso de modalidades de participação exclusiva de pessoas com deficiência visual, a classe é precedida pela letra "B" de "blind" (cego). Quanto maior o número da classe de um atleta, menor é o comprometimento físico-motor ou visual do mesmo. A classificação recebida pelo competidor pode mudar durante sua carreira, de acordo com alterações em sua deficiência ou nos parâmetros de avaliação (COMITÊ Organizador dos Jogos Parapanamericanos, 2007).

$\mathrm{Na}$ modalidade natação, por exemplo, tem-se as seguintes classes (COMITÊ OrGANIZADOR DOS JoGOS PARAPANAMERICANOS, 2007):

- S1 a S10: atletas com deficiência físico-motora;

- S11 a S13: atletas cegos e com deficiência visual;

- S14: atletas com deficiência mental.

O surgimento do esporte para pessoas com deficiência, e seu crescimento em todo o mundo, fez com que gradativamente fossem criadas entidades 
internacionais, nacionais e regionais nas diversas áreas de deficiência e também em diferentes modalidades, com a responsabilidade de melhor administrá-lo. Tanto a organização das disputas no esporte adaptado, quanto a classificação dos atletas, seguem normas específicas de órgãos reguladores, que racionalizam e representam o componente burocrático desse universo. A função desses órgãos é muito semelhante à de uma instituição nacional reguladora de uma modalidade para nãodeficientes, ou seja, supervisionar o desenvolvimento e a condução de suas disputas e eventos, além de promover a participação de seus membros nos mesmos. Tais órgãos, que oferecem programas esportivos para pessoas com deficiência, podem ser classificados como organizações poliesportivas e monoesportivas (PACIOREK, 2004).

As organizações poliesportivas oferecem treinamento e competição para pessoas com deficiências específicas em diversas modalidades. Têm-se, como exemplos dessa categoria de organizaçôes, USCPAA (Associação dos Atletas com Paralisia Cerebral dos Estados Unidos); CBDC (Confederação Brasileira de Desportos para Cegos). As organizações monoesportivas promovem a participação em uma única modalidade esportiva, tanto para uma deficiência, quanto para deficiências múltiplas. Por exemplo: NARHA (Associação Norte-americana de Equitação para Portadores de Deficiência); CBBC (Confederação Brasileira de Basquetebol em Cadeira de Rodas). É importante citar também a ocorrência de um movimento de interação entre processos organizacionais do esporte olímpico e paraolímpico através de entidades reguladoras. Tal fenômeno se manifesta no fato de federaçóes de esportes olímpicos abarcarem a organização de modalidades paraolímpicas similares, como no caso da Federação Internacional de Tênis de Mesa (Federação Internacional de TÊNIS DE MESA, 2008). Modalidades paraolímpicas que não possuem entidade reguladora própria, ou lidam com mais de uma deficiência, como a natação, tem a figura do Comitê Paraolímpico Internacional como órgão responsável por sua normatização.

Existem inúmeras entidades reguladoras com autonomia parcialmente adquirida, pois em competiçōes específicas de determinada organização, as mesmas têm independência de atuação no gerenciamento da modalidade e do evento. Porém, quando se trata dos Jogos Paraolímpicos, a responsabilidade pela organização e regulação das regras de disputa cabe ao Comitê Paraolímpico Internacional (IPC), ao qual, nessa situação, as outras entidades se reportam.
O IPC surgiu a partir da criação de diferentes órgãos reguladores, somado à participação de diferentes áreas de deficiência, que gerou a necessidade de criação de um organismo para administrar e realizar os eventos com maior eficácia e que também pudesse ter voz junto ao Comitê Olímpico Internacional (IOC). Assim, quatro entidades internacionais (por área de deficiência) criaram, em 1982, o ICC - Comitê Internacional de Coordenação das Organizações Mundiais de Esporte para pessoas com deficiência. O ICC, com o apoio do Comitê Olímpico Internacional, organizou os Jogos Paraolímpicos de Seul, Coréia do Sul, em 1988, usando pela primeira vez e de forma oficial as mesmas instalações dos Jogos Olímpicos. O sucesso do trabalho, e a crescente pressão dos países membros por mais representatividade no ICC, levaram à fundação, em 1989, do Comitê Paraolímpico Internacional - IPC, com um modelo democrático de organização, que passou a ser a principal entidade do Movimento Paraolímpico (COMITÊ OrganIZADOR dos Jogos Parapanamericanos, 2007).

O IPC é responsável pela organização e execução dos Jogos Parolímpicos de Verão e de Inverno, das competiçōes multideficiências, como os campeonatos mundiais, e por projetos de fomento desenvolvidos ao redor do mundo. Os Jogos Paraolímpicos de inverno de Lillehamer, Noruega, em 1994, foram os primeiros realizados sob a responsabilidade do IPC. Em 19 de junho de 2001 o IPC assinou um acordo com o IOC tornando obrigatório, a partir dos Jogos de Pequim 2008, que qualquer cidade que apresente sua candidatura para os Jogos Olímpicos, tanto de Verão, quanto de Inverno, englobe na mesma proposta a realização dos Jogos Paraolímpicos. Uma das condiçóes desse tratado é o limite de 4.000 atletas paraolímpicos até 2016 (COMITÊ Organizador dos Jogos Parapanamericanos, 2007). O estreitamento das relações entre o movimento olímpico e paraolímpico se dá também nas diversas comissões e comitês do IOC e IPC, participando em conjunto na busca de melhores caminhos para o esporte mundial (SENATORE, 2006).

Embora trabalhe de forma associada com o IOC, o IPC ainda não tem a mesma abrangência internacional e o mesmo acesso a recursos financeiros, assim como todo o esporte paraolímpico. Do atual quadro de atletas paraolímpicos de alto rendimento brasileiros só um pequeno número são profissionais do esporte. A maioria depende de auxílios como a "Bolsa-incentivo" fornecida pelo governo federal e o Comitê Paraolímpico Brasileiro (CPB), que constitui, segundo esse próprio órgão regulador, uma doação 
aos atletas, não configurando vínculo empregatício (Comitê Paraolímpico Brasileiro, 2008).

É importante fazer uma ressalva quanto à organização do esporte para surdos, pois essa deficiência não faz parte dos Jogos Paraolímpicos por opção própria de seus representantes. A principal competição internacional desses atletas se dá nos Jogos Mundiais para Surdos (PACIOREK, 2004).

\section{Relação entre o esporte olímpico e paraolímpico}

De acordo com o referencial adotado neste trabalho, o fenômeno paraolímpico, embora herdeiro dos princípios fundamentais do esporte moderno, tem origem sócio-histórica e razões para seu surgimento diferentes do olímpico. O primeiro deriva do esporte adaptado, com sua gênese motivada pelo senso de reabilitação e inclusão social, enquanto o segundo surgiu de conformações sociais ligadas à transmissão de valores morais e da tendência da sociedade ao controle da violência, principalmente em relação aos jogos populares.

Ao analisar os objetos "esporte olímpico" e "esporte paraolímpico" numa perspectiva sociológica, pode-se notar que em alguns aspectos ambos se encontram no mesmo estágio de amadurecimento e de perspectivas em relação à sociedade contemporânea, como no caso das manifestações comerciais presentes também no esporte adaptado, a exemplo da Copa do Mundo Paraolímpica VISA. Porém, em outras questôes existem certas diferenças quanto à interpretação de conformações sociais e à forma com que eles respondem, ou responderam, às demandas da sociedade.

\section{Similaridades entre o esporte olímpico e paraolímpico}

Um primeiro ponto a ser abordado, com relação às similaridades, é o fato do esporte paraolímpico ter sido criado num período em que o olímpico vislumbrava grande importância cultural e política em nível mundial. Isso reforça o fato de ambos terem origens embrionárias semelhantes, e a versão adaptada desse fenômeno ter se inspirado em determinaçôes construídas historicamente pelo outro.

Por isso é possível associar a definição de esporte adotada anteriormente na introdução deste trabalho (MARQUES, 2007) tanto ao fenômeno olímpico quanto paraolímpico, assim como também se podem observar as categorias fundamentais do esporte moderno de GUTTMANN (1978) em ambos, sempre considerando que tais características foram herdadas pelo fenômeno contemporâneo e acrescidas de um caráter mercadológico e heterogêneo.
Outro ponto importante é a existência do que Pierre de Coubertin admitia ser a filosofia do olimpismo, "citius-fortius-altius", que traduz o desejo de superação presente no esporte e que motiva o atleta a ser mais poderoso, capaz de efetuar mais realizações, de competir, presente tanto no esporte olímpico quanto no paraolímpico (LANDrY, 1995). O movimento paraolímpico, ao longo de sua história, tem se desenvolvido pautado nos ideais olímpicos de "fair play", busca por melhora de performances, autocontrole, rejeição à discriminação, promoção do respeito mútuo, cooperação e paz entre as nações. Por isso, não pode ser desvinculado do olimpismo, embora trabalhe pautado em conceitos filosóficos específicos, ainda se apóia em algumas diretrizes que constam na Carta Olímpica. E não há nada nesse documento que impeça ligações tanto filosóficas quanto práticas entre os dois movimentos (LANDRY, 1995).

O esporte adaptado pode ser praticado, tanto no alto rendimento, como na escola, também com propósitos de lazer e de forma terapêutica e de reabilitação, dentro de programas formais, abertos ou não-estruturados (WINNICK, 2004). Nos dias atuais é possível afirmar que tanto a pessoa com deficiência quanto o não-deficiente pode ser atleta, profissional ou não, ou se relacionar de outra maneira com o fenômeno esportivo, em qualquer ambiente em que se encontre, sob todos os sentidos que a prática possa tomar.

Quanto à estrutura organizacional de ambos, é possível encontrar caminhos semelhantes. Enquanto no esporte olímpico segue-se o IOC, Comitês Olímpicos Nacionais e Federaçôes, o paraolímpico se apóia no IPC, Comitês Paraolímpicos Nacionais e Federações.

\section{Diferenças entre o esporte olímpico e paraolímpico}

Numa outra perspectiva, pode-se apontar diferenças entre os dois objetos de análise. Por exemplo, diferenças históricas quanto às gêneses do esporte olímpico e paraolímpico. Embora ambos sejam herdeiros do esporte moderno, 
criado entre os séculos XVIII e XIX na Inglaterra, o esporte olímpico teve seu surgimento motivado pela necessidade de organização e homogeneização das regras das modalidades e universalização de suas práticas durante os primeiros anos de 1900. Além disso, teve sua origem nutrida pelo desejo aristocrático de diferenciação social através do esporte e, além de divulgar valores morais positivos em sua essência através do espírito olímpico, foi uma forma de afirmação da prática esportiva como lazer amador de nobres, com tempo livre e condições sócio-econômicas para tal.

Já o esporte paraolímpico se apropriou, numa época mais recente (metade do século XX), da herança do esporte moderno, buscando uma alternativa para a recuperação e reabilitação de sujeitos com lesão medular, e se estruturou de forma a atender ao público com deficiência, não como um diferenciador social, mas sim como um movimento de luta pela inclusão social através da prática esportiva.

Além de terem sua gênese em épocas distintas, os objetos de análise deste trabalho tiveram motivações diferentes para seu surgimento. Enquanto o primeiro recebeu estímulos da sociedade relacionados à luta de classes, impulsão da era industrial e à busca de racionalização das práticas, o segundo, sendo mais recente, e num tempo em que o grupo social já havia incorporado tais valores, foi influenciado pela fase posterior à 2a. Guerra Mundial e a necessidade de reconstrução das instituições, relações sociais e a inclusão de sujeitos que, embora possuíssem alguma deficiência, muitas vezes causadas pelos conflitos militares, eram tão capazes de realizações quanto indivíduos sem deficiência.

Outra questão que os diferencia sócio-historicamente é que o esporte olímpico incorporou características integrais do esporte contemporâneo, ou seja, além de se manifestar de forma heterogênea, tem atualmente seu eixo principal guinado pela disputa no alto rendimento e a busca do lucro. Enquanto que o paraolímpico incorporou principalmente tendências esportivas contemporâneas ligadas ao caráter heterogêneo das formas de manifestação, pois o profissionalismo e a exploração comercial ainda se encontram em fase inicial e em forma embrionária se comparada ao esporte olímpico. Embora o esporte adaptado seja um fenômeno promissor comercialmente.

Esse fato é reforçado por dados ligados à espetacularização e divulgação do fenômeno esportivo na era contemporânea. Podem-se notar grandes diferenças entre a exploração comercial do esporte paraolímpico e olímpico. Por exemplo, os Jogos Olímpicos de Pequim, China, realizados em 2008, têm 55 empresas como patrocinadores oficiais (COMitê Olímpico Internacional, 2008), enquanto que os Jogos Paraolímpicos, realizados no mesmo local, nas mesmas instalações, e num período próximo, têm apenas 31 empresas nessa condição (Comitê Paraolímpico Internacional, 2008). É importante ressaltar a diferença da importância comercial entre os dois objetos, mesmo ambos tendo o mesmo objetivo e serem organizados por órgãos associados (Comitê Olímpico Internacional - IOC e Comitê Paraolímpico Internacional - IPC).

Ao visitar as "home pages" dos dois principais órgãos reguladores do esporte (IOC - www.olympic. org e IPC - www.paralympic.org), pode-se notar que o primeiro anuncia a realização de doações de sua parte a refugiados de guerra, enquanto o segundo anuncia que aceita doaçóes para trabalhos ligados ao movimento paraolímpico.

Embora, como já foi citado, a estrutura organizacional de ambos os objetos de análise sejam semelhantes, pode-se notar algumas diferenças. Por exemplo, a questão de comitês nacionais. Embora a paraolimpíada seja um movimento mais recente, é necessário que os países participantes tenham comitês paraolímpicos próprios que os representem. Porém, um caso a parte é o dos Estados Unidos, que se vincula ao IPC através do U.S. Paralympic, um núcleo do Comitê Olímpico Norte Americano que funciona como um comitê paraolímpico. (PACIOREK, 2004).

Além disso, embora possam ser encontradas tanto federaçôes monoesportivas quanto poliesportivas em ambos os casos, a motivação para essa ocorrência é diferente. Enquanto que no esporte olímpico é possível encontrar, por exemplo, a FIVB (Federação Internacional de Voleibol - modalidades Voleibol de quadra e de areia) ou a FIFA (Federação Internacional de Futebol - modalidades Futebol, Futsal e "Beach Soccer"), entidades que cuidam de mais de uma modalidade por razões comerciais e organizacionais, no paraolímpico tem-se, por exemplo, a Confederação Brasileira de Desportos para Cegos (CBDC), que cuida de diversas modalidades buscando facilitar as adaptações de regras, instalaçōes e procedimentos para um público específico.

Nessa tendência pode-se apontar a transformação de modalidades originadas no esporte olímpico, como por exemplo, o futebol, para práticas voltadas aos atletas paraolímpicos, como o "Futebol de 5" para pessoas com deficiência visual, que contém bandas laterais que impedem a saída da bola do 
campo de jogo e guizo na bola, para que os jogadores a localizem através da audição.

Além das coincidências e divergências específicas, é possível apontar algumas características próprias do esporte paraolímpico que, além de adaptar práticas para pessoas com deficiências, também cria manifestações originais visando possibilitar novas oportunidades para esses sujeitos. Por exemplo, existem algumas modalidades esportivas exclusivas do esporte paraolímpico, como o "Goalball", jogado por pessoas com deficiência visual, sem nenhum correspondente direto no esporte olímpico. Outro fato específico do movimento paraolímplico é a busca por distanciamento da perspectiva de recuperação e reabilitação e a aproximação da prática competitiva como fim em si mesma, num crescimento notável do alto rendimento adaptado. Um exemplo desse fato é a ocorrência do "doping" no esporte paraolímpico, que pode ser interpretado como um sinal de que a preocupação e as recompensas pela vitória passam a ser, para muitos, o ponto central da prática.

Nota-se, nessa perspectiva, uma evolução histórica do esporte paraolímpico que passou por fases distintas do olímpico, mas que pode, num futuro próximo, chegar ao mesmo ponto, principalmente em relação à perspectiva comercial. Isso pode ser percebido através de uma análise da história do esporte adaptado, que surgiu com propósitos de reabilitação e inclusão, passou por uma fase de aceitação e divulgação e, atualmente, vem rumando deste estágio para a comercialização de seus símbolos e produtos, adotando o modelo competitivo hegemônico.

\section{Considerações finais}

Com base na análise realizada, é possível afirmar que o "esporte olímpico" e o "esporte paraolímpico" são fenômenos com gêneses motivadas por princípios distintos. Ou seja, possuem características próprias que tornam cada um deles original. Porém, devido à herança comum relativa aos fundamentos do esporte moderno, no decorrer da história podemse observar pontos de aproximação entre eles, sendo possível afirmar que em alguns aspectos eles se assemelham, enquanto que em outros divergem.

Quanto às características econômicas, o esporte olímpico encontra-se mais desenvolvido do que o paraolímpico, ou numa situação de melhor aproveitamento das possibilidades de atuação frente ao esporte-espetáculo. Isso pode acontecer devido à história mais longa do primeiro e também à existência de alguns preconceitos na sociedade contemporânea, relativos ao esporte adaptado. A falta de conhecimento e a crença de que pessoas com deficiência estão fadadas à inatividade física podem ser fatores que atrapalhem o desenvolvimento econômico do esporte paraolímpico. Mas, ao que tudo indica, trata-se de um fenômeno que, a cada dia, aumenta sua legitimidade e amplia suas fronteiras. Mas é preciso ter presente também que ainda existe um longo caminho a ser percorrido rumo a aceitação e abrangência já alcançadas pelo esporte olímpico. Fundamentados em histórias paralelas do ponto de vista de suas gêneses, pode-se notar que em alguns pontos ambos os objetos se aproximam, principalmente no trabalho conjunto entre os Comitês Olímpico e Paraolímpico Internacional e na realização dos Jogos Olímpicos e Paraolímpicos.

Quanto às principais características do esporte contemporâneo - a comercialização do fenômeno e suas heterogêneas formas de manifestação - tanto o esporte olímpico quanto o paraolímpico podem se expressar de maneiras variadas, atendendo às indicaçôes do Modelo de concepção das formas de manifestação do esporte (MARQues, 2007). O esporte paraolímpico, é preciso destacar, é um fenômeno mais recente e se encontra, portanto, num estágio anterior de exploração das potencialidades econômicas do esporte. Isto pode sugerir que as características dos objetos analisados tendam a se aproximar no futuro, visto a necessidade de busca de recursos financeiros para a própria sobrevivência na sociedade contemporânea, porém sempre mantendo algum grau de especificidade.

Finalmente, cabe destacar que enquanto a olimpíada enfrenta uma crise na preservação de seus ideais, que correm o risco de cair no esquecimento pela ação do esporte-espetáculo, a necessidade iminente de vitórias e principalmente de lucros, o esporte paraolímpico necessita aumentar sua divulgação e geração de recursos financeiros, para ampliar sua presença na sociedade contemporânea. 


\begin{abstract}
Olympic and paraolympic sports: coincidences, divergences and specifities under a contemporary perspective

This text presents an analysis of the adapted sport, focusing on the Paralympics games, an event realized in association with the Olympic Games. It tries to point similarities and differences between the two events, considered as forms of expression of the contemporary sport, detaching characteristics as the organization, relationship with the market and popularization forms. The main described differences refer to the genesis of the two objects, besides the largest vocation of the Olympic sport for the market insertion. As for the similarities, it stands out the presence in both of the characteristics of the modern sport generated in the XIX century, besides the similar organizational conceptual structures. It can still be pointed some specific points of the adapted sport, as own modalities as an example of the "Goalball."
\end{abstract}

UnITERMS: Sociology of sport; Adapted sport; Olympic games; Paralympics.

\title{
Referências
}

BOURDIEU, P. Programa para uma sociologia do esporte. In: BORDIEU, P. Coisas ditas. São Paulo: Brasiliense, 1990. p.207-20.

COMITÊ OLÍMPICO INTERNACIONAL. Olympic charter. Lausanne: International Olympic Committee, 2007. Disponível em: <http://www.olympic.org/uk/index_uk.asp>. Acesso em: 10 abr. 2008.

COMITÊ ORGANIZADOR DOS JOGOS PARAPANAMERICANOS. Cartilha para professores: Jogos Parapanamericanos 2007, Rio de Janeiro, 2007.

COMITÊ PARAOLÍMPICO BRASILEIRO. Disponível em: <http://www.cpb.org.br>. Acesso em: 10 abr. 2008.

COMITÊ PARAOLÍMPICO INTERNACIONAL. Disponível em: <http://www.paralympic.org/release/Main_Sections_Menu/index.html>. Acesso em: 10 abr. 2008.

DUARTE, E.; SANTOS, T.P. Adaptação e inclusão. In: DUARTE, E.; LIMA, S.M.T. Atividade física para pessoas com necessidades especiais: experiências e intervenções pedagógicas. Rio de Janeiro: Guanabara Koogan, 2003. p.93-9. DUNNING, E. Prefácio. In: ELIAS, N.; DUNNING, E. A busca da excitação. Lisboa: Difusão Editorial, 1992. p.11-37. DUNNING, E.; CURRY, G. Escolas públicas, rivalidade social e o desenvolvimento do futebol. In: GEBARA, A.; PILATTI, L.A. (Orgs.). Ensaios sobre história e sociologia nos esportes. Jundiaí: Fontoura, 2006. p.45-76.

ELIAS, N.; DUNNING, E. A busca da excitação. Lisboa: Difusão Editorial, 1992. p.187-222.

FEDERAÇÃO INTERNACIONAL DE TÊNIS DE MESA. Disponível em: <http://www.ittf.com/competitions/competitions2.asp?Competition_ID=1755\&category=POG>. Acesso em: 26 maio 2008.

GUTTMANN, A. From ritual to record: the nature of modern sports. New York: Columbia University Press, 1978.

LANCELOTTI, S. Olimpíadas 100 anos: história completa dos jogos. São Paulo, Nova Cultural, 1996.

LANDRY, F. Paralympic games and social integration. Barcelona: Centre d’Estudis Olimpics UAB, 1995. Disponível em: <http://olympicstudies.uab.es/pdf/wp041_eng.pdf>. Acesso em: 10 abr. 2008.

MARCHI JUNIOR, W. Bourdieu e a teoria do campo esportivo. In: PRONI, M.W.; LUCENA, R.F. (Orgs.). Esporte: história e sociedade. Campinas: Autores Associados, 2002, p.77-111.

MARQUES, R.F.R. Esporte e qualidade de vida: reflexão socioloógica (2007). Dissertação (Mestrado) - Faculdade de Educação Física, Universidade Estadual de Campinas, Campinas, 2007.

MARQUES, R.F.R.; GUTIERREZ, G.L.; ALMEIDA, M.A.B. Esporte na empresa: a complexidade da integração interpessoal. Revista Brasileira de Educação Física e Esporte, São Paulo, v.20, n.1, p.27-36, 2006.

. O esporte contemporâneo e o modelo das formas de manifestação do esporte. Revista Conexóes, Campinas, v.6, n.2, p.42-61, 2008. Disponível em: <http://polaris.bc.unicamp.br/seer/fef/viewarticle.php?id=347\&layout=abstract>. Acesso em: 21 ago. 2008.

PACIOREK, M.J. Esportes adaptados. In: WINNICK, J.P. Educação física e esportes adaptados. Barueri: Manole, 2004. p.37-52. 
PILZ, G.A. Sociologia do esporte na Alemanha. Revista Estudos históricos: esporte e lazer, v.1, n.23, p.3-17, 1999. Disponível em: <http://www.cpdoc.fgv.br/revista/arq/256.pdf>. Acesso em 10 jan. 2007.

PRONI, M.W. Esporte-espetáculo e futebol-empresa. 1998. Tese (Doutorado) - Faculdade de Educação Física, Universidade Estadual de Campinas, Campinas, 1998.

RUBIO, K. Do olimpo ao pós-olimpismo: elementos para uma reflexão sobre o esporte atual. Revista Paulista de Educação Física, São Paulo, v.2, n.16, p.130-43, 2002.

SENATORE, V. Paraolímpicos do futuro. In: CONDE, A.J.M.; SOUZA SOBRINHO, P.A.; SENATORE, V. Introdução ao movimento paraolímpico: manual de orientação para professores de Educação Física. Brasília: Comitê Paraolímpico Brasileiro, 2006. Disponível em: http://www.informacao.srv.br/cpb/pdf/introducao.pdf. Acesso em: 15 jun. 2008.

STIGGER, M.P. Educação física, esporte e diversidade. Campinas: Autores Associados, 2005.

TUBINO, M.J.G. Dimensóes sociais do esporte. São Paulo: Cortez/Autores Associados, 1992.

. Esporte, política e jogos olímpicos. In: TAMBUCCI, P.L.; MARIZ DE OLIVEIRA, J.G.; COELHO SOBRINHO, J. Esporte e jornalismo. São Paulo: CEPEUSP, 1997. p.19-23.

WADDINGTON, I. A história recente do uso de drogas nos esportes: a caminho de uma compreensão sociológica. In: GEBARA, A.; PILATTI, L.A. (Orgs.). Ensaios sobre história e sociologia nos esportes. Jundiaí: Fontoura, 2006. p.13-43. WINNICK, J.P. Introdução à educação física e esportes adaptados. In: WINNICK, J.P. Educação física e esportes adaptados. Barueri: Manole, 2004. p.3-19.

\begin{tabular}{|c|c|}
\hline $\begin{array}{r}\text { ENDEREÇO } \\
\text { Renato Francisco Rodrigues Marques } \\
\text { Faculdade de Educação Física } \\
\text { Universidade Estadual de Campinas } \\
\text { Av. Érico Verissimo, 701 - C.P. } 614 \\
\text { 13081-970 - Campinas - SP - BRASIL } \\
\text { e-mail: renato.marques@yahoo.com.br }\end{array}$ & $\begin{array}{l}\text { Recebido para publicação: 11/09/2008 } \\
\text { Aceito: 04/08/2009 }\end{array}$ \\
\hline
\end{tabular}

